\title{
Bicarbonate ingestion has no ergogenic effect on consecutive all out sprint tests in BMX elite cyclists
}

\author{
Mikel Zabala • Ana B. Peinado • \\ Francisco J. Calderón · Javier Sampedro • \\ Manuel J. Castillo • Pedro J. Benito
}

\begin{abstract}
The aim of the present study was to examine the effect of sodium bicarbonate ingestion on consecutive "all out" sprint tests, analyzing the acid-base status and its influence on performance and perceived effort. Ten elite bicycle motocross (BMX) riders $(20.7 \pm 1.4$ years, training experience 8-12 years) participated in this study which consisted of two trials. Each trial consisted of three consecutive Wingate tests (WTs) separated by 15 min recovery. Ninety minutes prior to exercise subjects ingested either $\mathrm{NaHCO}_{3}^{-}\left(0.3 \mathrm{~g} \mathrm{~kg}^{-1}\right.$ body weight $)$ or placebo. Blood samples were collected for the assessment of blood acid-base status: bicarbonate concentration $\left(\left[\mathrm{HCO}_{3}{ }^{-}\right]\right), \mathrm{pH}$, base excess (BE) and blood lactate concentration ([La $\left.{ }^{-}\right]$). Performance variables of peak power (PP), mean power
\end{abstract}

M. Zabala and A. B. Peinado contributed equally to this work.

M. Zabala

Department of Physical Education and Sport,

University of Granada, Granada, Spain

M. Zabala

Spanish Cycling Federation, Madrid, Spain
Communicated by Susan A. Ward.

A. B. Peinado $(\triangle)$ · F. J. Calderón · P. J. Benito Department of Health and Human Performance, Technic University of Madrid, Martín Fierro 7, 28040 Madrid, Spain

e-mail: anabelen.peinado@upm.es

J. Sampedro

Department of Sports, Technic University of Madrid,

Madrid, Spain

M. J. Castillo

Department of Medical Physiology, School of Medicine, University of Granada, Granada, Spain (MP), time to peak power and fatigue index were calculated for each sprint. Significant differences $(p<0.05)$ were observed in acid-base variables [pH before WT1: $7.47 \pm$ 0.05 vs. $7.41 \pm 0.03 ;\left[\mathrm{HCO}_{3}{ }^{-}\right]$before WT1: $29.08 \pm 2.27$ vs. $22.85 \pm 0.24 \mathrm{mmol} \mathrm{L}^{-1}$ (bicarbonate vs. placebo conditions, respectively)], but there were not significant differences in performance variables between trials [PP WT1: $1,610 \pm 373$ vs. $1,599 \pm 370 \mathrm{~W}$; PP WT2: $1,548 \pm 460$ vs. $1,570 \pm 428 \mathrm{~W}$; PP WT3: $1,463 \pm 361$ vs. $1,519 \pm$ 364 W. MP WT1: $809 \pm 113$ vs. $812 \pm 108$ W; MP WT2: $799 \pm 135$ vs. $799 \pm 124 \mathrm{~W}$; MP WT3: $762 \pm 165$ vs. $782 \pm 118 \mathrm{~W}$ (bicarbonate vs. placebo conditions, respectively)]. Rating of perceived effort (RPE) was not influenced nor ratings of perceived readiness. Sodium bicarbonate ingestion modified significantly the blood acidbase balance, although the induced alkalosis did not improve the Wingate test performance, RPE and perceived readiness across three consecutive WTs in elite BMX cyclists.

Keywords Bicarbonate - Wingate test . Acid-base balance $\cdot$ Performance $\cdot$ RPE .

Perceived readiness

\section{Introduction}

Bicycle motocross (BMX) is an Olympic sport since Beijing 2008 that consists of repeated cycling trials (approximately $350 \mathrm{~m}$ and $\sim 40 \mathrm{~s}$ each) pedaling across an irregular sand-track that includes curves and jumps. The aim of the competition is to reach the finish line in the best position of the eight riders competing together in each trial. The competition usually involves at least three qualification series, quarterfinals, semi-finals, and final (a minimum 
of three trials for those competitors eliminated in the qualification series, and six trials or more depending on the number of competitors for those that reach the final). Between each trial there is a recovery period of $15-30 \mathrm{~min}$, more time in the first qualification series $(\sim 30 \mathrm{~min})$ and less in the last series $(\sim 15 \mathrm{~min})$. So, these kinds of short and "all out" efforts have been characterized as highly "acid", as well as the recoveries between them as a key point to better perform and succeed in competitions (Zabala et al. 2009).

Over the past decades, numerous studies have demonstrated that increases in the extracellular buffer concentration, via the oral ingestion of an alkaline solution such as sodium bicarbonate $\left(\mathrm{NaHCO}_{3}{ }^{-}\right)$may enhance human exercise performance (Forbes et al. 2005; Linderman and Fahey 1991; McNaughton et al. 1997, 1999; Requena et al. 2005; Sostaric et al. 2006; Stephens et al. 2002). The suggested beneficial effects of this induced an increase in extracellular proton buffer capacity (Linderman and Fahey 1991; Street et al. 2005), increased muscle phosphofructokinase, phosphorylase and pyruvate dehydrogenase activities (Hollidge-Horvat et al. 2000), enhanced muscle lactate and hydrogen ion $\left(\mathrm{H}^{+}\right)$release from working muscles (Mainwood and Worsley-Brown 1975) and a preservation of membrane excitability during muscle fatigue by its effect on potassium $\left(\mathrm{K}^{+}\right)$, sodium $\left(\mathrm{Na}^{+}\right)$and chlorine $\left(\mathrm{Cl}^{-}\right)$fluxes (Sostaric et al. 2006). Hydrogen ion efflux out of the muscle cell has been reported to be inhibited by extracellular acidosis and enhanced by a greater extracellular buffer concentration (Bishop and Claudius 2005). In general, studies that have found an increase in exercise performance after $\mathrm{NaHCO}_{3}{ }^{-}$ingestion used intermittent or continuous exercise regimens that produced a large acid-base disturbance (Linderman and Fahey 1991; Requena et al. 2005). During continuous dynamic exercises the performance has been generally improved when the protocol selected exhausted the subjects in 1-10 min (Requena et al. 2005). However, when high-intensity exercises of shorter duration ( $30-40 \mathrm{~s})$ were examined conflicting results were reported (Linderman and Fahey 1991; Requena et al. 2005). The studies that have analyzed the effect of $\mathrm{NaHCO}_{3}{ }^{-}$administration on Wingate test (WT) performance have shown ergogenic (Douroudos et al. 2006; Inbar et al. 1983; Zinner et al. 2011) and non-ergogenic benefits (Parry-Billings and MacLaren 1986; Zabala et al. 2008). However, most of the abovementioned studies were performed in non-trained subjects and ingesting an oral drink solution instead capsules. It is well known that elite sprinters $(100-200 \mathrm{~m})$ produce an extremely high amount of $\mathrm{H}^{+}$and lactate during competitions. Several studies have shown that sprint-trained athletes during maximal short-term efforts present a greater force production capacity associated with a greater systemic acidosis in comparison with untrained or endurance trained subjects (Johansen and Quistorff 2003).

Given the widespread use of buffers between elite athletes (Requena et al. 2005) and its possible beneficial effect on BMX performance and competition, we examine the effect of $\mathrm{NaHCO}_{3}{ }^{-}$loading on three consecutive Wingate tests (WTs), analyzing the acid-base status and its influence on performance and perceived effort in elite BMX cyclists. We hypothesized that bicarbonate ingestion improves performance across three consecutive WTs interspersed by $15 \mathrm{~min}$.

\section{Methods}

Approach to the problem

During the experiment the subjects were taking part in an official monitoring phase with the National Team so their eating and physical activity patterns were controlled accurately. The experimental phase took place during the end part of the preseason period. All the subjects visited the laboratory on three occasions. On the first visit, subjects were familiarized with the test procedure (Fig. 1). Experimental data were collected during the subsequent two visits. The two treatment conditions, $\mathrm{NaHCO}_{3}{ }^{-}$ingestion $\left(\mathrm{NaHCO}_{3}{ }^{-}\right)$and placebo (PLC), were administered in a counterbalanced, crossover, randomly assigned, doubleblind manner, with each trial separated by 4 days. Each subject was instructed to refrain from caffeine, alcohol, and exercise for $24 \mathrm{~h}$ before each trial, and studies were carried out at the same time of day.

\section{Participants}

Ten elite BMX riders from the Spanish National Team volunteered to participate in this study. Their mean $( \pm \mathrm{SD})$ age, height and body mass were $20.7 \pm 1.4$ years, $178.3 \pm 2.1 \mathrm{~cm}$ and $77.9 \pm 2.1 \mathrm{~kg}$, respectively. The training experience was $8-12$ years. All the cyclists studied were full time semi-professionals who trained $4-6 \mathrm{~h}$ per day. Subjects were experienced in all testing procedures as a result of their participation in previous performance assessment (more than 10 times in the last 2 years). None of the subjects were involved in any form of nutritional supplementation that may have compromised the administration of the $\mathrm{NaHCO}_{3}{ }^{-}$. Written consent was obtained from each subject after explanation of the purposes and associated risks of the study protocol. The experiment was conducted in compliance with the Declaration of Helsinki and was approved by the University Ethics Committee for Human Studies. 


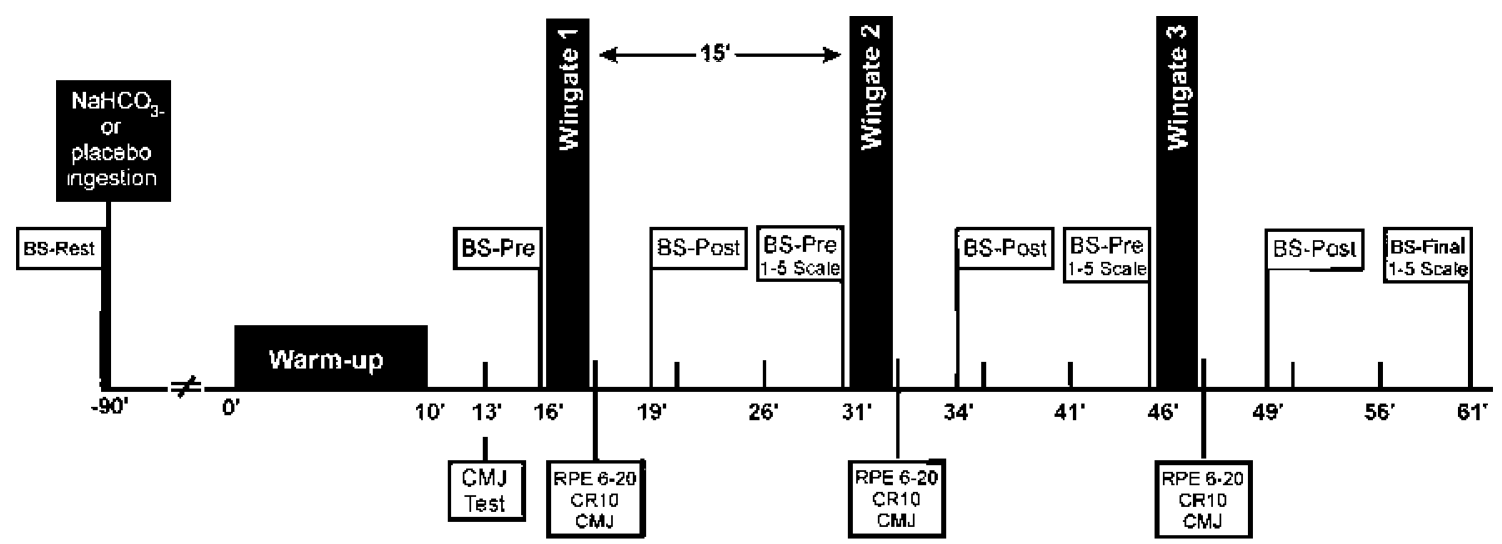

Fig. 1 Experimental protocol

\section{Procedures}

Experimental protocol is illustrated in Fig. 1. In each testing session, the subjects performed a standardized warm-up which involved $10 \mathrm{~min}$ of cycle ergometry (Lode Excalibur, Groningen, The Netherlands) at an intensity of $100 \mathrm{~W}$. After 3 min rest the subjects performed a vertical jump test as indicator of instantaneous power production. The vertical jump test involved two counter-movement jumps (CMJ test; Ergojump, Rome, Italy) interspersed by $1 \mathrm{~min}$ rest. Only the best jump from each subject was used in data analysis. Counter-movement jump test was selected based on the high correlation found by Zabala et al. 2008, between peak power in WT and power obtained by means of CMJ performance $(r=0.91, p<0.01)$. This test was followed by a $3 \mathrm{~min}$ rest period before the first of the three $30 \mathrm{~s}$ WTs (WT1, WT2 and WT3) were undertaken. Wingate test was performed to replicate a widely used laboratory test, as well as a similar effort to the BMX competition (Zabala et al. 2008, 2009). All WTs were performed on the same ergometer with 15 min passive recovery between each one. Subjects exercised against the standard resistive load $(0.7 \mathrm{~N} / \mathrm{m} \times \mathrm{kg}$ body mass). Peak and mean power (PP and MP, respectively), time to peak power (TPP) and fatigue index were downloaded to an on-line PC. Subjects were given verbal encouragement throughout the tests. Immediately after each WT rating of perceived exertion (RPE) and vertical jump height (CMJ test) were obtained. Rating of perceived exertion was measured with the Borg 15 point scale (RPE 6-20) (Borg et al. 1985) and with a 10-point category-ratio (RPE CR10) (Noble et al. 1983).

Capillary blood samples (BS) were collected from a fingertip for the assessment of blood acid-base status. Blood samples were drawn (1) on rest (before to substances ingestion), (2) prior to each WT (BS-Pre), (3) 3 min after completion of each WT (BS-Post), and 4) after $15 \mathrm{~min}$ of recovery. Blood was collected into heparinized capillary tubes for subsequent determination of acid-base status (bicarbonate concentration: $\left[\mathrm{HCO}_{3}{ }^{-}\right], \mathrm{pH}$ and base excess: BE) using a blood gas analyser ABL77 (Radiometer, Copenhagen, Denmark). Blood lactate concentration ( $\left[\mathrm{La}^{-}\right]$) was analyzed by enzymatic method using the YSI 1500 (Yellow Springs Instruments Co., Yellow Springs, USA).

The value for perceived readiness ( $1-5$ scale) (Nurmekivi et al. 2001) was also taken prior to the next WT. This scale determines in the grade of recovery that subjects perceived from 1-point ("not recovered at all") to 5-points ("completely recovered").

Prior to all trials subjects reported to the laboratory in a 3-h post-absorptive state. For the $\mathrm{NaHCO}_{3}{ }^{-}$ingestion trial subjects ingested an individualized number of gelatin capsules containing $\mathrm{NaHCO}_{3}^{-}\left(0.3 \mathrm{~g} \mathrm{~kg}^{-1}\right.$ body weight $)$ or placebo and were consumed with as much water as required. Both substances were ingested $90 \mathrm{~min}$ prior to exercise as recommended by different authors (Linderman and Fahey 1991; McNaughton et al. 1999; Requena et al. 2005). Due to potential mild gastrointestinal discomfort associated with ingestion of $\mathrm{NaHCO}_{3}{ }^{-}$, subjects were asked throughout the pre-exercise and exercise periods to rate their stomach comfort level and their bowel urgency rating (subjective feeling of urge to defecate). None of the participants reported serious gastrointestinal distractions.

\section{Statistical analysis}

All values are reported as mean \pm SD. Two-way analysis of variance (ANOVA) ( 2 treatments $\times 8$ measurements) with repeated measures were used to determine differences between treatments at each exercise period for all the acidbase and workload dependent variables. Two-way ANOVA ( 2 treatments $\times 3$ measurements) with repeated measures were used to determine differences between treatments at each exercise period for all the RPE, perceived readiness and CMJ-dependent variables. Compound symmetry, or sphericity, was verified by the Mauchley test. When the 
assumption of sphericity was not met, the significance of $F$ ratios was adjusted according to the Greenhouse-Geisser procedure. Multiple comparisons were made with the Bonferroni post hoc test. The level of statistical significance was set at $\alpha \leq 0.05$ for all analyses.

\section{Results}

Acid-base variables

The ingestion of $\mathrm{NaHCO}_{3}{ }^{-}$had the expected effect on blood acid-base status. Statistical differences were observed between both conditions $\left(\mathrm{NaHCO}_{3}{ }^{-}\right.$and placebo), showing that alkalosis was reached with the proposed $\mathrm{NaHCO}_{3}{ }^{-}$doses (Fig. 2).

The repeated measures ANOVA revealed a significant effect on $\mathrm{pH}$ for treatment $(p<0.05$; Fig. $2 \mathrm{a})$. The $\mathrm{pH}$ values measured before the start the WT1 were $7.47 \pm$ $0.05\left(\mathrm{NaHCO}_{3}{ }^{-}\right)$and $7.41 \pm 0.03$ (placebo) $(p<0.05)$. The $\mathrm{pH}$ remained reduced $(p<0.05)$ across experimental protocol in the placebo condition. There was also a significant effect on $\left[\mathrm{HCO}_{3}^{-}\right]$for treatment $(p<0.05$; Fig. 2b). The $\left[\mathrm{HCO}_{3}{ }^{-}\right]$was significantly higher in the $\mathrm{NaHCO}_{3}{ }^{-}$than in the placebo condition before (Pre WT)
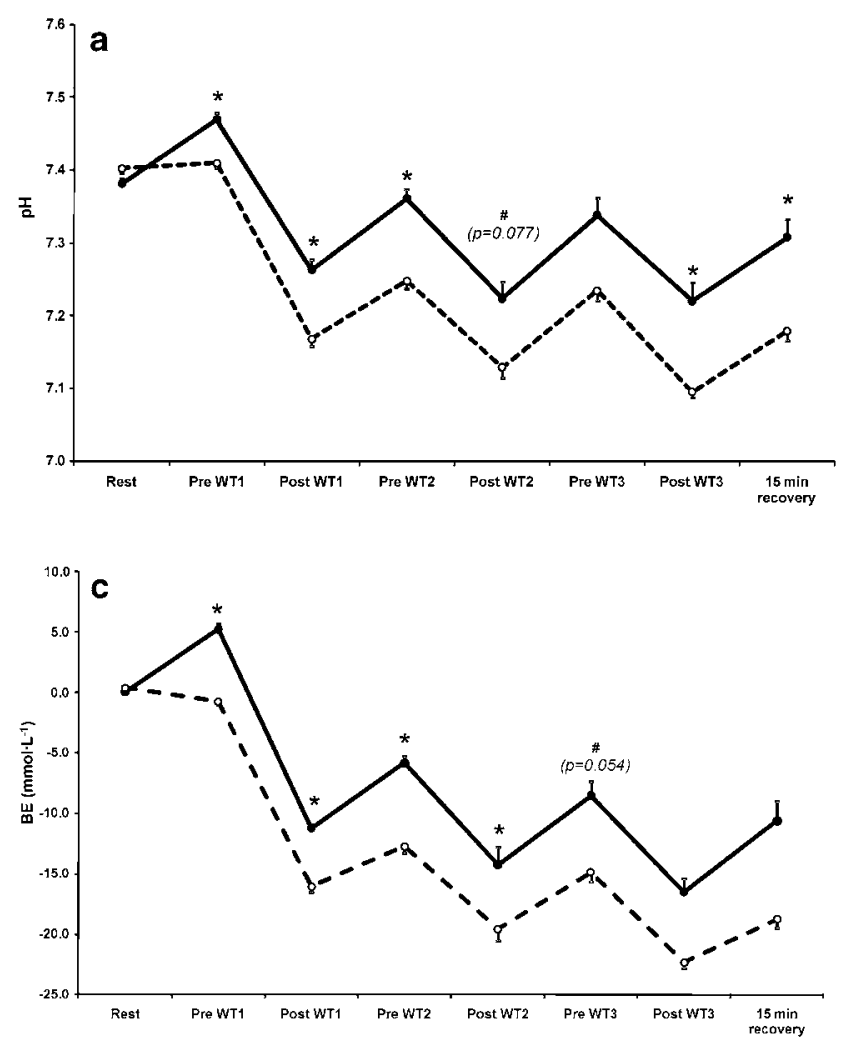

Fig. $2 \mathrm{pH}(\mathbf{a})$, bicarbonate concentration $\left(\left[\mathrm{HCO}_{3}{ }^{-}\right]\right)(\mathbf{b})$, base excess (BE) (c) and lactate concentration $\left(\left[\mathrm{La}^{-}\right]\right.$) (d) for the placebo (discontinuous line) and $\mathrm{NaHCO}_{3}^{-}$(continuous line) conditions. each WT and 3 min after (Post WT) each WT. The effect on base excess response was significant for treatment $(p<0.05$; Fig. $2 c)$. The base excess was significantly higher in the $\mathrm{NaHCO}_{3}{ }^{-}\left(5.24 \pm 2.19 \mathrm{mmol} \mathrm{L}^{-1}\right)$ than in the placebo condition $\left(-0.73 \pm 1.28 \mathrm{mmol} \mathrm{L}^{-1}\right)$ before the start the WT1 (90 min after ingestion) and remained elevated along the WTs. No significant differences were found in the $\left[\mathrm{La}^{-}\right]$between both conditions (Fig. 2d), with higher values (non-significant) in the $\mathrm{NaHCO}_{3}{ }^{-}$condition.

\section{Performance}

Table 1 shows the mean values of performance for the three WTs under $\mathrm{NaHCO}_{3}{ }^{-}$ingestion and placebo conditions. The induced alkalosis had no effect on performance during the three consecutives WTs. There were no significant differences in PP and TPP in any of the three WTs between the two treatments. Moreover, no significant differences were found in MP or fatigue index (Table 1).

No significant differences were observed in CMJ test after WT1 $(32.16 \pm 2.90$ vs. $32.15 \pm 2.33 \mathrm{~cm})$, WT2 $(30.14 \pm 3.26$ vs. $29.72 \pm 2.51 \mathrm{~cm})$ and WT3 between the $\mathrm{NaHCO}_{3}{ }^{-}$and placebo conditions, although performance tended to be better for the $\mathrm{NaHCO}_{3}{ }^{-}$condition (Post WT3: $28.66 \pm 4.77$ vs. $27.96 \pm 4.30 \mathrm{~cm}$ ).
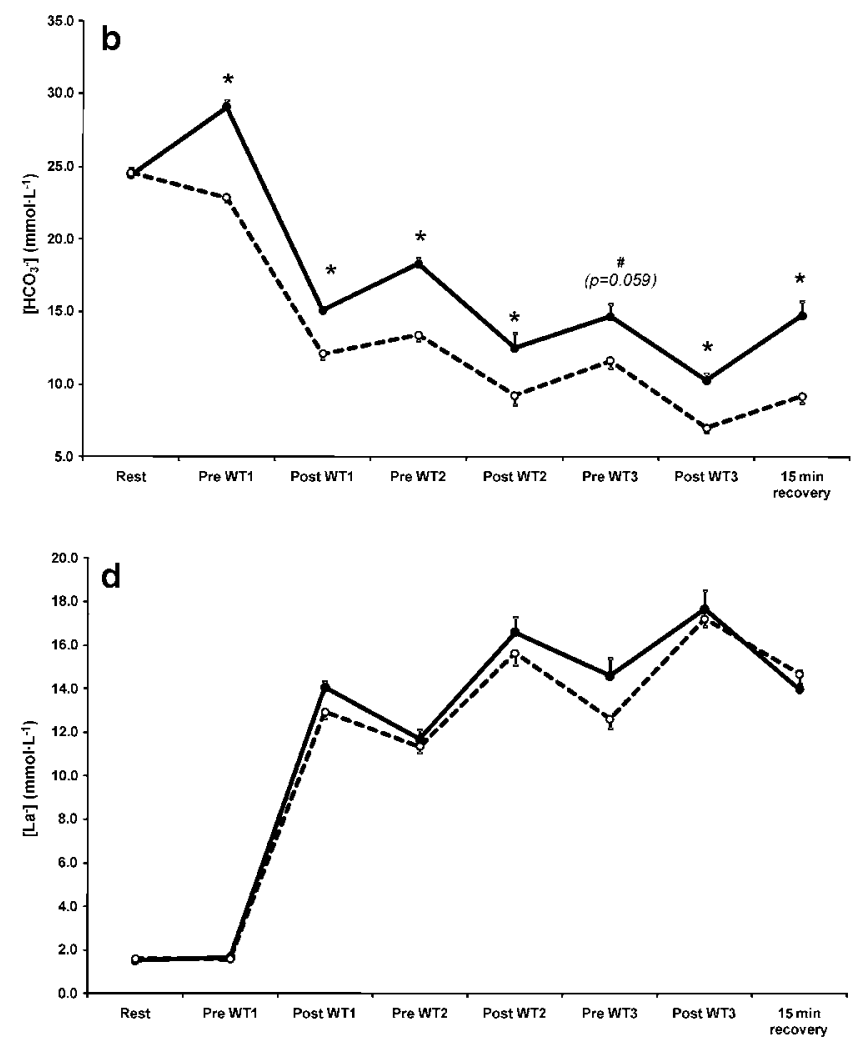

Values are shown as means \pm SEM. * Indicates a significant difference from placebo condition $(p<0.05)$. \# Indicates trends of significance 
Table 1 Performance in each Wingate test (WT1, WT2 and WT3) under $\mathrm{NaHCO}_{3}{ }^{-}$and placebo conditions

\begin{tabular}{|c|c|c|c|}
\hline & WT1 & WT2 & WT3 \\
\hline \multicolumn{4}{|l|}{$\mathrm{PP}(\mathrm{W})$} \\
\hline $\mathrm{NaHCO}_{3}^{-}$ & $1,610 \pm 373$ & $1,548 \pm 460$ & $1,463 \pm 361$ \\
\hline Placebo & $1,599 \pm 370$ & $1,570 \pm 428$ & $1,519 \pm 364$ \\
\hline \multicolumn{4}{|l|}{ TPP (s) } \\
\hline $\mathrm{NaHCO}_{3}^{-}$ & $4.4 \pm 0.3$ & $4.6 \pm 0.4$ & $4.6 \pm 0.7$ \\
\hline Placebo & $4.5 \pm 0.4$ & $4.5 \pm 0.3$ & $4.6 \pm 1.3$ \\
\hline \multicolumn{4}{|l|}{$\mathrm{MP}(\mathrm{W})$} \\
\hline $\mathrm{NaHCO}_{3}^{-}$ & $809 \pm 113$ & $799 \pm 135$ & $762 \pm 165$ \\
\hline Placebo & $812 \pm 108$ & $799 \pm 124$ & $782 \pm 118$ \\
\hline \multicolumn{4}{|c|}{ Fatigue index $\left(\mathrm{W} \mathrm{s}^{-1}\right)$} \\
\hline $\mathrm{NaHCO}_{3}^{-}$ & $42.9 \pm 15.6$ & $40.1 \pm 21.1$ & $40.4 \pm 23.6$ \\
\hline Placebo & $42.5 \pm 15.5$ & $42.2 \pm 17.4$ & $40.7 \pm 15.1$ \\
\hline
\end{tabular}

Values are shown as means \pm SD

$M P$ mean power, $P P$ peak power, $T P P$ time to peak power

Rating of perceived exertion and readiness

No significant differences were found for RPE 6-20 between conditions (Post WT1: $17.72 \pm 1.25$ vs. $17.50 \pm$ 1.20; Post WT2: $17.89 \pm 1.45$ vs. $17.89 \pm 1.29$ and Post WT3: $18.44 \pm 1.13$ vs. $18.33 \pm 1.35$, between the $\mathrm{NaHCO}_{3}{ }^{-}$ and placebo conditions, respectively). The same results were obtained with the scale RPE CR10 (Post WT1: $8.83 \pm 0.75$ vs. $8.17 \pm 0.59$; Post WT2: $9.06 \pm 0.74$ vs. $8.83 \pm 0.46$ and Post WT3: $10.28 \pm 0.67$ vs. $9.22 \pm 0.52$, between the $\mathrm{NaHCO}_{3}{ }^{-}$and placebo conditions, respectively). There were no significant differences for perceived readiness (1-5 scale) between the $\mathrm{NaHCO}_{3}{ }^{-}$and placebo conditions before WT2 $(4.70 \pm 0.33$ vs. $4.85 \pm 0.32$, respectively), before WT3 $(4.10 \pm 0.62$ vs. $3.70 \pm 1.12$, respectively) and after WT3 (3.55 \pm 0.79 vs. $3.38 \pm$ 1.19 , respectively).

\section{Discussion}

The main finding of the present study was that $\mathrm{NaHCO}_{3}{ }^{-}$ ingestion altered significantly the blood acid-base balance, although the induced alkalosis did not improve the performance across three consecutive WTs in elite BMX cyclists. The $\mathrm{NaHCO}_{3}{ }^{-}$ingestion resulted in an elevated blood buffering status prior to the first Wingate test, with that elevation being sustained throughout the following WTs. The results of the present study, in agreement with other investigations (Parry-Billings and MacLaren 1986; Stephens et al. 2002; Vanhatalo et al. 2010; Zabala et al. 2008), demonstrate no ergogenic effect of sodium bicarbonate ingestion on high-intensity exercise performance, despite significant blood alkalosis. Other studies have reported performance improvements, due to an ergogenic benefit of $\mathrm{NaHCO}_{3}^{-}$supplementation during multiple bouts of high-intensity exercise (Bishop and Claudius 2005; Bishop et al. 2004; Douroudos et al. 2006; Price et al. 2003).

The induced blood alkalosis may improve $\mathrm{H}^{+}$efflux out of the muscle cell and thereby limiting the effects of the reduced intracellular $\mathrm{pH}\left(\mathrm{pH}_{\mathrm{i}}\right)$ determined by strenuous exercise (Bishop et al. 2004; Linderman and Fahey 1991; Requena et al. 2005; Street et al. 2005). It is generally accepted that a decreasing $\mathrm{pH}_{\mathrm{i}}$ during exercise induces allosteric inhibition of the rate-limiting enzymes phosphofructokinase and glycogen phosphorylase, decreases release of $\mathrm{Ca}^{2+}$ from the sarcoplasmatic reticulum, and reduces the number and force of muscle cross-bridge activations (Linderman and Fahey 1991). Anaerobic glycolysis is associated with the intracellular accumulation of $\mathrm{H}^{+}$, which have been implicated as a cause of muscular fatigue (Spriet et al. 1985) and previous results report that administration of alkalotic agents may improve performance during high-intensity exercise by reducing the decline in $\mathrm{pH}$ (Hollidge-Horvat et al. 2000).

A key point could be that, although we did not measure $\mathrm{pH}_{\mathrm{i}}$, other studies have reported that induced alkalosis does not affect $\mathrm{pH}_{\mathrm{i}}$ until blood $\mathrm{pH}$ is above 7.5 (Bishop et al. 2004) so skeletal muscle's properties would not be changed to produce a gain in performance. If $\mathrm{pH}_{\mathrm{i}}$ would not be different between conditions, this could explain why we did not find differences on performance, despite blood lactate concentration being greater in bicarbonate condition $\left(14.07 \pm 1.35 \mathrm{mmol} \mathrm{L}^{-1}\right.$ Post WT1) in contrast with placebo condition $\left(12.93 \pm 1.52 \mathrm{mmol} \mathrm{L}^{-1}\right.$ Post WT1). It has been suggested that lactate efflux from muscle is higher as a result of extracellular alkalosis (Mainwood and WorsleyBrown 1975), thus in our study it is not likely an increased muscle glycogen use, although we did not measure muscle lactate concentration. The mechanism that may explain the greater $\left[\mathrm{La}^{-}\right]$in bicarbonate condition in the present study is a higher efflux of $\mathrm{H}^{+}$and lactate due to the increased activity of the lactate/ $\mathrm{H}^{+}$transporter (Bishop and Claudius 2005) rather than a higher anaerobic energy contribution. This is in agreement with the lack of effect on performance. In contrast, other authors have reported an increase in muscle lactate accumulation with induced alkalosis (Bishop et al. 2004; Bouissou et al. 1988) increasing anaerobic energy contribution and improving repeated-sprint ability (Bishop and Claudius 2005; Bishop et al. 2004).

The failure of alkalosis to increase WT performance may be explained because of the duration and nature of the effort developed in the test: (1) by an insufficient time during the exercise to allow a significant difference in $\mathrm{H}^{+}$ efflux from the muscle fibers or an inability to generate a 
sufficient difference in $\mathrm{H}^{+}$gradient to produce a difference between trials (Forbes et al. 2005; Linderman and Fahey 1991; Mainwood and Worsley-Brown 1975; Marx et al. 2002; McCartney et al. 1983; Street et al. 2005) and, in the same way, (2) the fact that the test was continuous and not involving maximal intermittent efforts as other authors successfully tested (Bishop and Claudius 2005; Bishop et al. 2004; Price et al. 2003). Both of these could result in no significant differences in $\mathrm{pH}_{\mathbf{i}}$, in which case muscle performance would be expected to be similar (HollidgeHorvat et al. 2000; Marx et al. 2002). Several in situ and in vivo 31P-MRS studies have demonstrated a strong correlation between a decline in $\mathrm{pH}_{\mathrm{i}}$ and force production (Forbes et al. 2005; Pedersen et al. 2005), although the role of intramuscular acidosis on muscle fatigue is controversial, especially when other factors that change during intense exercise may interact with elevated $\mathrm{H}^{+}$to impair exercise performance (Cairns 2006). Sostaric et al. (2006) have proposed that the major beneficial effect of alkalosis on muscle performance might be the preservation of muscle membrane excitability by its integrated effects on $\mathrm{K}^{+}, \mathrm{Na}^{+}, \mathrm{Cl}^{-}$and lactate homeostasis. The correlations observed between decreased muscle force and increased intracellular concentrations of lactate may be considerably overestimated and other beneficial effects have been possibly overlooked (Allen et al. 2008; Robergs et al. 2004) as in example centrally in the brain. In fact, different authors (Cairns 2006; Lamb and Stephenson 2006; Prakash 2008; Robergs 2008) recently defend that lactate per se is not a problem in exercise and fatigue, and may even be useful during exercise as a fuel. Similarly, it is not clear which mechanisms explain the enhancement in performance after bicarbonate intake observed in several studies. In summary, induction of a metabolic alkalosis may result in a complex series of metabolic effects as a lower intramuscular acidosis (Forbes et al. 2005; Stephens et al. 2002), changes in the activity of key regulatory enzymes and fuel utilization (Forbes et al. 2005; Hollidge-Horvat et al. 2000 ), a preservation of muscle cell membrane excitability (Sostaric et al. 2006), or a central effect in the brain as some authors have recently studied (Yamanaka et al. 2010), that may permit under certain conditions of exercise intensity and duration increase the muscle performance.

Other studies have analyzed the effect of sodium bicarbonate administration prior to one WT (Douroudos et al. 2006; Inbar et al. 1983; Parry-Billings and MacLaren 1986; Zabala et al. 2008) with no ergogenic effect. Only Inbar et al. (1983) and Douroudos et al. (2006) observed a significant increase in mean power following alkaline treatment but showing no effect on other performance variables measured. Douroudos et al. (2006) suggested that the improvement in performance depends on the dose used and the high dose is the most effective $\left(0.5 \mathrm{~g} \mathrm{~kg}^{-1}\right.$ body weight). In contrast, MeNaughton (1992) tested five different doses of sodium bicarbonate (from 0.1 to $0.5 \mathrm{~g} \mathrm{~kg}^{-1}$ body weight) and found that performance was improved with increasing the dose to $0.3 \mathrm{~g} \mathrm{~kg}^{-1}$ body weight. Moreover, the highest value of cycling work and peak power were achieved with that dose. For the present investigation we chose a dose of $0.3 \mathrm{~g} \mathrm{~kg}^{-1}$ body weight, extensively used previously (Requena et al. 2005; Siegler and Hirscher 2010; Stephens et al. 2002; Vanhatalo et al. 2010; Zabala et al. 2008) and proposed to be the optimal amount to be ergogenic (Hollidge-Horvat et al. 2000; Linderman and Fahey 1991; McNaughton et al. 2008; Stephens et al. 2002) and the most appropriate to obtain a blood alkalosis in human without side effects (i.e., gastrointestinal distress) (Vanhatalo et al. 2010). Thus, the observed lack of improvement in WT performance in the present study may consequently not be due to the sodium bicarbonate administration protocol used, and perhaps the improvements observed in other studies (Douroudos et al. 2006; Price et al. 2003; Siegler and Hirscher 2010) may be partly due to the type of ingestion (drink solution). In our study, subjects ingested an individualized number of gelatin capsules containing $\mathrm{NaHCO}_{3}{ }^{-}\left(0.3 \mathrm{~g} \mathrm{~kg}^{-1}\right.$ body weight) or placebo, used by other authors (Bishop and Claudius 2005; Bishop et al. 2004), instead of dissolved in water or juice. Although in some cases subjects reported similar taste of the experimental and placebo treatment solutions (Price et al. 2003), we tasted $\mathrm{NaHCO}_{3}{ }^{-}$compared with $\mathrm{NaCl}\left(0.05 \mathrm{~g} \mathrm{~kg}^{-1}\right.$ body weight $)$ solutions in previous studies (Zabala et al. 2008) and found their taste completely different, so athletes could know they were different substances (worse and harder the taste of $\mathrm{NaHCO}_{3}{ }^{-}$). McClung and Collins (2007) compared the performance contribution made by expectancy alone, with the improvements of $\mathrm{NaHCO}_{3}{ }^{-}$ingestion, and their results suggests that some of the documented benefits may be achieved through psychologically based expectancy effect alone (Beedie and Foad 2009; Trojian and Beedie 2008). Subjects' belief in the efficacy of a placebo treatment might significantly influence findings in experimental research (McClung and Collins 2007; Trojian and Beedie 2008). Finally, the occurrence of gastrointestinal distress associated with ingestion of $\mathrm{NaHCO}_{3}{ }^{-}$may increase the subjects' belief in what they have ingested (Trojian and Beedie 2008). In our study, the subjects did not experience gastrointestinal annoyances or abdominal discomfort, so this had no influence on performance.

To the authors knowledge only two studies have reported the effect of $\mathrm{NaHCO}_{3}{ }^{-}$ingestion on multiple WTs. Parry-Billings and MacLaren (1986) proposed a series of $3 \mathrm{WTs}$ separated by $6 \mathrm{~min}$ recovery periods. The effect on WT performance was small and non-significant. These results are in agreement with those observed in the 
present study. However, a direct comparison between studies is difficult, since the present study used $15 \mathrm{~min}$ recovery between WTs in simulating a BMX final series. In a previous work our research group (Zabala et al. 2008) examined the effect of $\mathrm{NaHCO}_{3}{ }^{-}$ingestion on performance of three WTs separated by $30 \mathrm{~min}$ recovery (simulating first qualification series) and obtained similar results; none had effect on performance and RPE. Taking into account these studies and the present one, we could argue that the recovery time used does not influence the performance, and the key point could be the type of exercise (intermittent vs. continuous). So for future research we suggest the use of a more specific test based in the field conditions during BMX competitions (freewheeling whilst cornering or jumping), that is an all-out intermittent exercise of $45 \mathrm{~s}$ of duration approximately.

In the present study changes in CMJ performance immediately after each WT was taken as an indirect indicator of the fatigue in the lower body fast motor units. CMJ performance was not significantly improved, although tended to be better after WT3 during the bicarbonate condition in comparison with placebo (Post WT3: $28.66 \pm 4.77$ vs. $27.96 \pm 4.30 \mathrm{~cm}$ ). This improvement could reflect a faster recovery process in those motor units recruited (Zabala et al. 2008).

Acid-base balance has been shown by several studies to mediate the intensity of subjective perception of exertion (RPE) during high-intensity as well as intermittent arm and leg exercise (Robertson et al. 1986; Swank and Robertson 2002). Rating of perceived exertion was related with $\mathrm{pH}$ and strongly related with bicarbonate concentration (Price et al. 2003). In this regard, Robertson et al. (1986) suggested that the mechanism underlying the relationship between acid-base balance and RPE during exercise may involve deleterious effects of accumulation of intracellular $\mathrm{H}^{+}$on muscle fatigue. The results of the present study show that RPE measured immediately after each WT, using two scales (6-20 and CR10), was not affected by bicarbonate ingestion. These results disagree with those published previously (Robertson et al. 1986; Swank and Robertson 2002) showing a lower RPE under alkalotic condition. However, other studies have published similar RPE between conditions, showing no effect on perceived exertion (Artioli et al. 2007; Price et al. 2003; Siegler and Hirscher 2010; Zabala et al. 2008). This discrepancy may be related with difference in the metabolic demands of the exercise task chosen (Zabala et al. 2008). In the same way, we did not observe improvements on perceived readiness, in contrast with the results obtained by other authors (Swank and Robertson 2002; Zabala et al. 2008), although these improvements could be related with the placebo effect discussed above because of the drink solution used instead of gelatin capsules. It could be argued that similar to the lack of effect in $\mathrm{pH}_{\mathrm{i}}$ could happen in the brain to alter perception of effort or readiness, as we did not find any effect in RPE values between each condition at the time blood $\mathrm{pH}$ was altered but not above 7.5 (Bishop et al. 2004).

In summary, sodium bicarbonate ingestion modified significantly the blood acid-base balance, although the induced alkalosis did not improve the Wingate test performance, CMJ, RPE and perceived readiness across three consecutive WTs in elite BMX cyclists. These results show that bicarbonate ingestion has no effect on performance, at least in the conditions of the present study.

Acknowledgments The authors gratefully acknowledge the team manager of the BMX Spanish National Team, Mr. Miguel HernándezPariente, for his interest and collaboration, and Mr. Manuel MateoMarch, Dr. Ángel Gutiérrez, and Mr. Cristóbal Sánchez-Muñoz, for the technical support. Also, we want to thank the athletes for their effort and professionalism.

\section{References}

Allen DG, Lamb GD, Westerblad H (2008) Skeletal muscle fatigue: cellular mechanisms. Physiol Rev 88:287-332

Artioli GG, Gualano B, Coelho DF, Benatti FB, Gailey AW, Lancha $\mathrm{AH} \mathrm{Jr}$ (2007) Does sodium-bicarbonate ingestion improve simulated judo performance? Int J Sport Nutr Exerc Metab 17:206-217

Beedie CJ, Foad AJ (2009) The placebo effect in sports performance: a brief review. Sports Med 39:313-329

Bishop D, Claudius B (2005) Effects of induced metabolic alkalosis on prolonged intermittent-sprint performance. Med Sci Sports Exerc 37:759-767

Bishop D, Edge J, Davis C, Goodman C (2004) Induced metabolic alkalosis affects muscle metabolism and repeated-sprint ability. Med Sci Sports Exerc 36:807-813

Borg G, Ljunggren G, Ceci R (1985) The increase of perceived exertion, aches and pain in the legs, heart rate and blood lactate during exercise on a bicycle ergometer. Eur J Appl Physiol Occup Physiol 54:343-349

Bouissou P, Defer G, Guezennec CY, Estrade PY, Sermurier B (1988) Metabolic and blood catecholamine responses to exercise during alkalosis. Med Sci Sports Exerc 20:228-232

Cairns SP (2006) Lactic acid and exercise performance: culprit or friend? Sports Med 36:279-291

Douroudos II, Fatouros IG, Gourgoulis V, Jamurtas AZ, Tsitsios T, Hatzinikolaou A, Margonis K, Mavromatidis K, Taxildaris K (2006) Dose-related effects of prolonged $\mathrm{NaHCO}_{3}$ ingestion during high-intensity exercise. Med Sci Sports Exerc 38:17461753

Forbes SC, Raymer GH, Kowalchuk JM, Marsh GD (2005) $\mathrm{NaHCO}_{3}{ }^{-}$induced alkalosis reduces the phosphocreatine slow component during heavy-intensity forearm exercise. J Appl Physiol 99:1668-1675

Hollidge-Horvat MG, Parolin ML, Wong D, Jones NL, Heigenhauser GJ (2000) Effect of induced metabolic alkalosis on human skeletal muscle metabolism during exercise. Am J Physiol Endocrinol Metab 278:E316-E329

Inbar O, Rotstein A, Jacobs I, Kaiser P, Dlin R, Dotan R (1983) The effects of alkaline treatment on short-term maximal exercise. J Sports Sci 1:95-101 
Johansen L, Quistorff B (2003) 31P-MRS characterization of sprint and endurance trained athletes. Int J Sports Med 24:183-189

Lamb GD, Stephenson DG (2006) Point: lactic acid accumulation is an advantage during muscle activity. J Appl Physiol 100:1410-1412 (discussion 1414)

Linderman J, Fahey TD (1991) Sodium bicarbonate ingestion and exercise performance. An update. Sports Med 11:71-77

Mainwood GW, Worsley-Brown P (1975) The effects of extracellular $\mathrm{pH}$ and buffer concentration on the efflux of lactate from frog sartorius muscle. J Physiol 250:1-22

Marx JO, Gordon SE, Vos NH, Nindl BC, Gomez AL, Volek JS, Pedro J, Ratamess N, Newton RU, French DN, Rubin MR, Hakkinen K, Kraemer WJ (2002) Effect of alkalosis on plasma epinephrine responses to high-intensity cycle exercise in humans. Eur J Appl Physiol 87:72-77

McCartney N, Heigenhauser GJ, Jones NL (1983) Effects of pH on maximal power output and fatigue during short-term dynamic exercise. J Appl Physiol 55:225-229

McClung M, Collins D (2007) "Because I know it will!": placebo effects of an ergogenic aid on athletic performance. J Sport Exere Psychol 29:382-394

McNaughton LR (1992) Bicarbonate ingestion: effects of dosage on 60 s cycle ergometry. J Sports Sci 10:415-423

McNaughton LR, Ford S, Newbold C (1997) Effect of sodium bicarbonate ingestion on high intensity exercise in moderately trained women. J Strength Cond Res 11:99-102

McNaughton L, Dalton B, Palmer G (1999) Sodium bicarbonate can be used as an ergogenic aid in high-intensity, competitive cycle ergometry of $1 \mathrm{~h}$ duration. Eur J Appl Physiol Occup Physiol 80:64-69

McNaughton LR, Siegler J, Midgley A (2008) Ergogenic effects of sodium bicarbonate. Curr Sports Med Rep 7:230-236

Noble BJ, Borg GA, Jacobs I, Ceci R, Kaiser P (1983) A categoryratio perceived exertion scale: relationship to blood and muscle lactates and heart rate. Med Sci Sports Exerc 15:523-528

Nurmekivi A, Karu T, Pihl E, Jurimae T, Lemberg H (2001) Blood lactate recovery and perceived readiness to start a new run in middle-distance runners during interval training. Percept Mot Skills 93:397-404

Parry-Billings M, MacLaren DP (1986) The effect of sodium bicarbonate and sodium citrate ingestion on anaerobic power during intermittent exercise. Eur J Appl Physiol Occup Physiol $55: 524-529$

Pedersen TH, de Paoli F, Nielsen OB (2005) Increased excitability of acidified skeletal muscle: role of chloride conductance. J Gen Physiol 125:237-246

Prakash ES (2008) Good bye "lactic acid"; hello lactate and acid. J Appl Physiol 105:363

Price M, Moss P, Rance S (2003) Effects of sodium bicarbonate ingestion on prolonged intermittent exercise. Med Sci Sports Exerc 35:1303-1308
Requena B, Zabala M, Padial P, Feriche B (2005) Sodium bicarbonate and sodium citrate: ergogenic aids? J Strength Cond Res 19:213-224

Robergs RA (2008) Science vs. personal bias in acid-base physiology. J Appl Physiol 105:363

Robergs RA, Ghiasvand F, Parker D (2004) Biochemistry of exerciseinduced metabolic acidosis. Am J Physiol 287:R502-R516

Robertson RJ, Falkel JE, Drash AL, Swank AM, Metz KF, Spungen SA, LeBoeuf JR (1986) Effect of blood pH on peripheral and central signals of perceived exertion. Med Sci Sports Exerc $18: 114-122$

Siegler JC, Hirscher K (2010) Sodium bicarbonate ingestion and boxing performance. J Strength Cond Res 24:103-108

Sostaric SM, Skinner SL, Brown MJ, Sangkabutra T, Medved I, Medley T, Selig SE, Fairweather I, Rutar D, McKenna MJ (2006) Alkalosis increases muscle $\mathrm{K}+$ release, but lowers plasma $[\mathrm{K}+]$ and delays fatigue during dynamic forearm exercise. J Physiol 570:185-205

Spriet LL, Matsos CG, Peters SJ, Heigenhauser GJ, Jones NL (1985) Effects of acidosis on rat muscle metabolism and performance during heavy exercise. Am J Physiol 248:C337-C347

Stephens TJ, McKenna MJ, Canny BJ, Snow RJ, McConell GK (2002) Effect of sodium bicarbonate on muscle metabolism during intense endurance cycling. Med Sci Sports Exerc 34:614-621

Street D, Nielsen JJ, Bangsbo J, Juel C (2005) Metabolic alkalosis reduces exercise-induced acidosis and potassium accumulation in human skeletal muscle interstitium. J Physiol 566:481-489

Swank AM, Robertson RJ (2002) Effect of induced alkalosis on perception of exertion during exercise recovery. J Strength Cond Res 16:491-499

Trojian TH, Beedie CJ (2008) Placebo effect and athletes. Curr Sports Med Rep 7:214-217

Vanhatalo A, McNaughton LR, Siegler J, Jones AM (2010) Effect of induced alkalosis on the power-duration relationship of "allout" exercise. Med Sci Sports Exerc 42:563-570

Yamanaka R, Yunoki T, Arimitsu T, Lian CS, Yano T (2010) Effects of sodium bicarbonate ingestion on EMG, effort sense and ventilatory response during intense exercise and subsequent active recovery. Eur J Appl Physiol

Zabala M, Requena B, Sanchez-Munoz C, Gonzalez-Badillo JJ, Garcia I, Oopik V, Paasuke M (2008) Effects of sodium bicarbonate ingestion on performance and perceptual responses in a laboratory-simulated BMX cycling qualification series. J Strength Cond Res 22:1645-1653

Zabala M, Sánchez-Muñoz C, Gutiérrez A (2009) La especialidad ciclista de BMX. In: Jiménez F, Terrados N, Villa JG (eds) Medicina y fisiología del ciclismo. Nexus Médica, Madrid

Zinner C, Wahl P, Achtzehn S, Sperlich B, Mester J (2011) Effects of bicarbonate ingestion and high intensity exercise on lactate and $\mathrm{H}(+)$-ion distribution in different blood compartments. Eur J Appl Physiol 